\title{
Information and learning technology (ILT) adoption among career and technical teachers in Malaysia
}

\begin{abstract}
This study investigated the diffusion of Information and Learning Technology (ILT) among career and technical educators in Malaysia. It was conducted at a large career and technical institute and utilized a non-experimental research approach. The results show that a majority of faculty members reported that ILT is important as a teaching tool, yet also suggest that few faculty members use it in their teaching practice. Compared to males, female faculty members owned significantly more personal computers. Faculty members who owned a personal computer rated higher on the variables of usage, knowledge, satisfaction, and support, and lower on frbarrier to useò than those who did not own a personal computer. The findings revealed that career and technical faculty members were most comfortable using familiar technologies including the Internet, word processing, and presentation software. The study suggests that career and technical training facilities in Malaysia should address general barriers and increase both technological and pedagogical support to successfully implement ILT in teaching and learning practice.
\end{abstract}

Keyword: Diffusion of information and learning technology; Technical educators; Career 